\title{
Extratos aquosos de plantas nativas com potencial uso no manejo da murcha bacteriana do tomateiro Ralstonia solanacearum (Smith 1896) Yabuuchi et al. 1996
}

\section{Raquel Maria da Silva', Wemerson Silva dos Santos², Edcleyton José de Lima ${ }^{2}$ e Kedma Maria Silva Pinto ${ }^{3}$}

\footnotetext{
${ }^{1}$ Universidade Federal do Agreste de Pernambuco. Programa de Pós-Graduação em Produção Agrícola. Av. Bom Pastor, S/№. Boa Vista. Garanhuns-PE, Brasil (CEP 55292-270). E-mail: raquel.maria18@hotmail.com.

${ }^{2}$ Universidade Federal do Agreste de Pernambuco. Curso de Graduação em Engenharia Agronômica. Av. Bom Pastor, S/№. Boa Vista. Garanhuns-PE, Brasil (CEP 55292-270).

${ }^{3}$ Universidade Federal do Agreste de Pernambuco. Av. Bom Pastor, S/№. Boa Vista. Garanhuns-PE, Brasil (CEP 55292-270).
}

Resumo. 0 trabalho objetivou avaliar o potencial biológico de extratos vegetais no manejo de Ralstonia solanacearum (Smith 1896) Yabuuchi et al. 1996. Foram preparados extratos aquosos das folhas de oito espécies vegetais (Chrysobalanus icaco, Caesalpinia leiostachya, Ziziphus joazeiro, Sideroxylon obtusifolium, Momordica charantia, Ceasalpinea pyramidalis, Cleome hassleriana e Dysphania ambrosioides). 0 antibiograma foi realizado por meio da deposição de alíquotas $(0,3 \mathrm{~mL})$ da suspensão bacteriana (108 UFC) em placas de Petri. Em seguida, discos de papel filtro, foram embebidos nas concentrações de 0 , $20,40,60$ e $80 \mathrm{mg} / \mathrm{mL}$ depositados na placa e incubadas por $48 \mathrm{~h}$ até a avaliação. In vivo, mudas de tomateiro da cultivar TY 2006 foram transplantadas em vasos contendo solo esterilizado, já inoculadas com o fitopatógeno $10^{8} \mathrm{UFC}$, neste ensaio, foi adicionado um tratamento com indutor de resistência D-L-aminobutírico (BABA) $\left(0,305\right.$ g i.a/1000 $\mathrm{mL}$ de $\left.\mathrm{H}_{2} \mathrm{O}\right)$. $\mathrm{O}$ delineamento estatístico foi inteiramente casualizado com 11 tratamentos e quatro repetições e as médias comparadas pelo teste de Tuckey $(\mathrm{p}<0,05)$. No antibiograma a unidade experimental foi representada por uma placa de Petri com quatro discos. Os dados foram submetidos à análise de variância (ANOVA) e as médias das concentrações dos extratos a uma análise de regressão. Os extratos de melão de são caetano, pau-ferro, catingueira, juá, erva de santa maria e quixabeira formaram halo de inibição sendo estatisticamente significativos. Em condições de casa de vegetação o extrato de quixabeira e BABA proporcionaram menor AACPD e maiores percentuais de
Recebido

$23 / 08 / 2020$

Aceito

$30 / 10 / 2020$

Disponível on line

02/11/2020

Publicado

31/12/2020

Acesso aberto

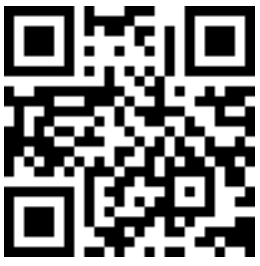

ORCID

(C) 0000-0002-5503-2072 Raquel Maria da Silva

(D) 0000-0002-3102-3024 Wemerson Silva dos Santos

ISSN 2359-1412/RBGAS-2020-0129/2020/7/17/17/1271

Rev. Bras. Gest. Amb. Sustent.

http://revista.ecogestaobrasil.net 
proteções da doença reduzindo a severidade, evidenciando suas potencialidades no manejo da fitobacteriose.

Palavras-chave: Fitobacteriose; Controle alternativo; Controle biológico; Tomate TY 2006.

Abstract. Aqueous extracts of native plants with potential use in the management of bacterial wilt in tomato Ralstonia solanacearum (Smith 1896) Yabuchi et al. 1996. This study aimed to evaluate the biological potential of plant extracts for the management of the bacterium Ralstonia solanacearum (Smith 1896) Yabuchi et al. 1996. To this end, leaf aqueous extracts of eight plant species (Chrysobalanus icaco, Caesalpinia leiostachya, Ziziphus joazeiro, Sideroxylon obtusifolium, Momordica charantia, Caesalpinia pyramidalis, Cleome hassleriana, and Dysphania ambrosioides) were prepared. The antibiogram was performed by depositing aliquots $(0.3 \mathrm{~mL})$ of bacterial suspension $\left(10^{8} \mathrm{CFU}\right)$ in Petri dishes. Then, filter paper discs were embedded at concentrations of $0,20,40,60$, and $80 \mathrm{mg} / \mathrm{mL}$ of bacterial suspension deposited in the dish and incubated for 48 hours until analysis. Tomato seedlings (cultivar TY 2006), already inoculated with the phytopathogen $\left(10^{8} \mathrm{CFU}\right)$, were transplanted (in vivo) to pots containing sterilized soil. This assay included treatment with DL-aminobutyric resistance inducer (BABA) $(0.305 \mathrm{~g}$ ia/ $1000 \mathrm{~mL}$ of $\mathrm{H}_{2} \mathrm{O}$ ). A completely randomized design was used, with eleven treatments and four replications, and the means were compared by the Tukey test $(p<0.05)$. In the antibiogram, each experimental unit consisted of a Petri dish with four discs. The data were subjected to analysis of variance (ANOVA) and the means of the extract concentrations were subjected to regression analysis. The extracts of "melão-de-são-caetano" (M. charantia), "pau-ferro" (C. leiostachya), "catingueira" (C. pyramidalis), "juazeiro" (Z. joazeiro), "erva-de-santa-maria" (D. ambrosioides), and "quixabeira" (S. obtusifolium) formed an inhibition halo, showing statistically significant difference. In greenhouse conditions, the extract of "quixabeira" and BABA provided a lower AUDPC (area under the disease progress curve) and higher percentages of protection from the disease by reducing its severity, evidencing their potential for the management of phytobacteriosis.

Keywords: Phytobacteriosis; Alternative control; Biologic control; TY 2006 tomato.
(1) 0000-0002-3635-1369
Edcleyton José de
Lima
다이 0000-0003-1595-2242
Kedma Maria Silva
Pinto

\section{Introdução}

O tomateiro Lycopersicum esculentum é a segunda hortaliça mais cultivada em todo o mundo (Costa, 2017). No Brasil, é cultivado em todas as regiões e ocupa a sétima posição na produção mundial de tomate industrial (Camargo Filho e Camargo, 2017). Em 2019, foram colhidas 4.075.890 t no Brasil com mais de 42\% da produção concentrada na região sudeste (1.717.618 t), sendo o Estado de São Paulo o maior produtor da região. No 
nordeste, foram colhidas $518.644 \mathrm{t}$, das quais, $47.094 \mathrm{t}$ foram produzidas no Estado de Pernambuco, no entanto o rendimento médio na região foi de $44.313 \mathrm{t} / \mathrm{ha}$, inferior à média nacional (70.168 t) (IBGE, 2019).

Dentre os fatores que contribuem para a redução da produção e incremento de custos na cultura, podem-se citar as doenças causadas por fungos, bactérias e vírus. As doenças de origem bacteriana, a murcha, causada pelo complexo Ralstonia solanacearum, tem grande importância em regiões tropicais e subtropicais, atingindo mais de 200 espécies de plantas (Mendes, 2017).

0 patógeno, que sobrevive no solo, penetra através de ferimentos ou aberturas naturais nas raízes e colonizam o xilema, interrompendo o fluxo de seiva bruta e provocando o sintoma típico da doença, a murcha que rapidamente pode causar morte da planta (Agrios, 2005). Neste cenário o estabelecimento de medidas fitossanitárias preventivas evitando a entrada da doença na área é o mais indicado, pois o patógeno pode sobreviver por longos períodos no solo (Lopes et al., 2015), por esta razão, a presença da bactéria Ralstonia solanacearum no solo é fator limitante para o cultivo do tomateiro. Além disso, Silva e Michereff (2016) afirmam que o patógeno apresenta uma enorme capacidade de dispersão por material propagativo, água e solos contaminados.

Somando-se a estas dificuldades, atualmente não há produtos químicos registrados no Ministério da Agricultura Pecuária e Abastecimento (MAPA), sendo recomendada a eliminação das plantas sintomáticas, o manejo da água de irrigação e do solo, dentre outras práticas (Costa, 2017). Assim, a utilização de um método alternativo pode se constituir como uma importante ferramenta para o controle da doença (Bettiol, 2019).

Nesta perspectiva, as plantas nativas podem constituir uma ferramenta de controle através de substâncias bioativas presentes, o Brasil, pela sua imensa diversidade vegetal pode ser considerado uma rica fonte destes compostos (Melo e Zacharias, 2019).

Portanto, o presente trabalho testou a validade da hipótese de que o uso de extratos aquosos proveniente de folhas de plantas nativas irá apresentar efeito antibacteriano à fitobactéria $R$. solanacearum in vitro e in vivo. Desta maneira, a referida pesquisa objetivou ampliar os conhecimentos sobre o controle da bactéria fitopatogênica R. solanacearum, investigando a utilização de extratos, com atividade antimicrobiana, para redução da severidade da doença.

\section{Material e métodos}

0 trabalho foi desenvolvido na Universidade Federal do Agreste de Pernambuco (UFAPE) no período de março a julho de 2017, coordenadas geográficas de referência $08^{\circ} 53^{\prime} 25^{\prime \prime}$ latitude $\mathrm{S}$ e $36^{\circ} 29^{\prime} 34^{\prime \prime}$ longitude 0 , com altitude média de $896 \mathrm{~m}$ e temperatura média de $21^{\circ} \mathrm{C}$ (Canuto et al., 2019).

Foi coletado material vegetal de oito espécies distintas (Tabela 1) nos Municípios de Garanhuns e Buíque, ambas pertencentes ao Estado de Pernambuco. Em seguida, o material foi conduzido ao Laboratório de Produção Vegetal e Análise de Sementes, onde foi pesado e lavado em água corrente e disposto em estufa de circulação forçada (TECNAL TE-394/3) sob temperatura de $65{ }^{\circ} \mathrm{C}$, sendo retiradas ao atingirem o peso constante, quando então foram trituradas em moinho de facas (TIPO WILLEY) e passadas em peneira de $2 \mathrm{~mm}$ para obtenção do material em pó.

Os extratos aquosos foram obtidos através do processo de infusão do material vegetal seco (pó) em água destilada, em uma proporção de 1:5 (p/v), durante $15 \mathrm{~min}$ a temperatura de $70^{\circ} \mathrm{C}$ em agitação magnética constante (VERTEX 78HW-1) e posteriormente filtrado em filtro de papel, obtendo-se o concentrado. 0 extrato foi submetido ao processo de congelamento para então ser liofilizado (TERRONI LD1500) e, por fim, identificado e armazenado sob refrigeração a $4,5^{\circ} \mathrm{C}\left( \pm 2{ }^{\circ} \mathrm{C}\right)$ para testes posteriores de atividade biológica in vitro e in vivo. 
Tabela 1. Espécies botânicas coletadas para obtenção dos extratos vegetais aquosos coletas nos Municípios de Garanhuns e Buíque, ambas em Pernambuco.

\begin{tabular}{|l|l|l|}
\hline Nome comum & Espécie & Família \\
\hline Ariú & Chrysobalanus icaco L. & Chrysobalanaceae \\
\hline Pau-ferro & Caesalpinia leiostachya (Benth.) Ducke. & Caesalpiniaceae \\
\hline Juazeiro & Ziziphus joazeiro Mart. & Rhamnaceae \\
\hline Quixabeira & $\begin{array}{l}\text { Sideroxylon obtusifolium (Humb. ex Roem. \& Schult.) } \\
\text { T.D. Penn. }\end{array}$ & Sapotaceae \\
\hline Melão-de-são-caetano & Momordica charantia L. & Cucurbitaceae \\
\hline Catingueira & Caesalpinea pyramidalis Tul. & Caesalpiniaceae \\
\hline Mussambê & Cleome hassleriana L. & Capparidacea \\
\hline Erva de santa maria & Dysphania ambrosioides L. & Amaranthaceae \\
\hline
\end{tabular}

Foram utilizados os oito extratos vegetais em cinco concentrações distintas (tratamentos), sendo elas 0 (controle), 20, 40, 60 e $80 \mathrm{mg} / \mathrm{mL}$, com quatro repetições para cada tratamento. 0 delineamento experimental foi inteiramente casualizado. Os dados foram submetidos a uma análise de variância (ANOVA) e as concentrações de cada extrato a uma análise de regressão pelo programa estatístico ASSISTAT 2010.

0 isolado de $R$. salanacearum CCRM Rs78 oriundo da coleção da Universidade Federal Rural de Pernambuco (sede), foi cultivado em um meio de cultura Kelman contendo solução cloreto de trifenil tetrazólio (C.T.T.) na concentração de $0,5 \%$ por $48 \mathrm{~h}$ a $26^{\circ} \mathrm{C}$, quando foram verificadas colônias com características típicas: mucoides, irregular e de colocação branca, que foram transferidas para um tubo de ensaio contendo água destilada esterilizada (ADE) para preparo da suspensão bacteriana, ajustada $\left(A_{580}=0,8\right)$ a concentração de $10^{8}$ de UFC/mL em espectrofotômetro visível (BIOCROM LIBRA 522). 0 antibiograma foi realizado através da deposição de alíquotas de $0,3 \mathrm{~mL}$ da suspensão bacteriana em placas de Petri, contendo o meio de cultura Kelman solidificado. Em seguida, discos de papel filtro (5,6 $\mathrm{mm}$ de diâmetro), foram embebidos nas referidas concentrações dos diferentes extratos vegetais aquosos esterilizados em filtros de membrana Millipore 0,22 $\mu \mathrm{m}$.

No tratamento controle do antibiograma $(0 \mathrm{mg} / \mathrm{mL})$ os discos de papel foram umedecidos com ADE. Os discos do experimento foram depositados em quatro pontos na placa de Petri. As quais foram mantidas em estufa incubadora B.O.D. (MARCONI) à temperatura constante de $30^{\circ} \mathrm{C}$ até o momento da avaliação, que foi realizada $48 \mathrm{~h}$ após a incubação através da mensuração do diâmetro dos halos de inibição do crescimento bacteriano em dois sentidos oposto, para posterior realização da média.

No ensaio in vivo, foram utilizados oito extratos vegetais em uma única dose $(40 \mathrm{mg} / \mathrm{mL})$ e mais três tratamentos, sendo um com plantas inoculadas e tratadas com água (relativo) e outro com plantas não inoculadas e tratadas com água (absoluta) e um tratamento com ácido D-L-aminobutírico (BABA) (positivo) na concentração de $(0,305 \mathrm{~g}$ i.a/1000 $\mathrm{mL}$ de água). 0 delineamento experimental foi inteiramente casualizado com onze tratamentos e quatro repetições, sendo a unidade experimental constituída por um vaso com uma planta. Os dados das variáveis epidemiológicas foram submetidos a uma análise de variância e as médias comparadas pelo teste de Tuckey a $5 \%$ de probabilidade.

As mudas de tomateiro, cultivar TY 2006 aos 20 dias após emergência foram inoculadas artificialmente. Para tal, as raízes foram feridas através de um corte com tesoura esterilizada e imersas em solução contendo a suspensão bacteriana $\left(A_{580}=0,8\right)$ por 5 min e a testemunha absoluta foi imersa em ADE. Depois da inoculação, as mudas foram transplantadas para vasos com capacidade $550 \mathrm{~mL}$, contendo solo, coletado da Fazenda Experimental da UFRPE (Garanhuns-PE) (Tabela 2) e esterilizado em autoclave. 
Após $24 \mathrm{~h}$ da inoculação, as plantas foram tratadas via solo com os extratos e com BABA, através da deposição de $50 \mathrm{~mL}$ de cada tratamento nos vasos e em dose única.

Tabela 2. Análise química do solo coletado na cidade Garanhuns-PE na profundidade de 0-20 cm.

\begin{tabular}{|c|c|c|c|c|c|c|c|c|c|c|c|}
\hline Amostra & $\mathrm{pH} \mathrm{H_{2 } \mathrm { O }}$ & $\mathbf{P}$ & $\mathrm{Ca}^{2+}$ & $\mathrm{Mg}^{2+}$ & $\mathrm{Na}^{2+}$ & $\mathbf{K}^{+}$ & $\mathrm{Al}^{3+}$ & $\mathrm{H}^{+}$ & $S$ & CTC & $\mathbf{V}$ \\
\hline & & & $\pi$ & & & & & - & m & & \\
\hline $\mathrm{Faz}$ & 5,4 & 2 & 0,95 & 095 & & & 25 & & & & \\
\hline
\end{tabular}

$\mathrm{S}=$ Soma de bases; $\mathrm{CTC}=$ Capacidade de troca catiônica; $\mathrm{V}=$ Saturação por bases; $\mathrm{Al}^{3+}=$ Acidez trocável.

O solo utilizado foi esterilizado em autoclave (PHOENIX LUTERCO - AV 100), em seguida foi transplantada uma muda de tomateiro da cultivar TY 2006 com cerca de 20 dias após a emergência em cada vaso já inoculadas artificialmente.

Após o aparecimento dos sintomas, foram avaliados os seguintes componentes epidemiológicos da doença: I - Período de incubação da doença (PI) calculado pelo número de dias entre a inoculação e o surgimento de sintomas; II - Severidade, avaliada com a escala diagramática descritiva; III - Área abaixo da curva de progresso da doença (AACPD), que será calculada pela expressão $\mathrm{AACPD}=\Sigma(\mathrm{yi}+(\mathrm{yi}+1) / 2$.dti, onde yi e yi+1 são os valores de severidade observados em duas avaliações consecutivas e dti o intervalo entre as avaliações e IV - Porcentagem de proteção. A severidade da doença foi avaliada através da escala diagramática (Figura 1), proposta por Gomes (1997), sendo então utilizado o método direto (Silva e Michereff, 2016).
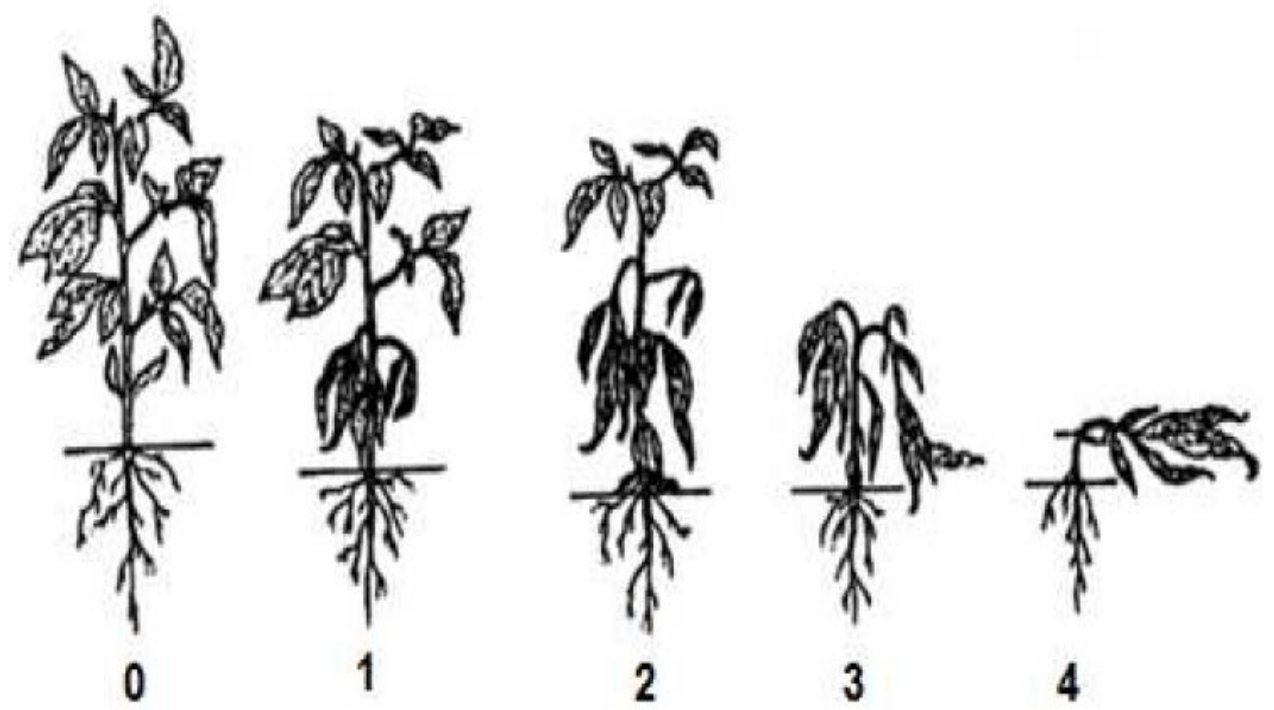

Figura 1. Escala diagramática para quantificação da severidade da murcha bacteriana do tomateiro (Ralstonia solanacearum), onde: 0 = ausência de sintomas; 1 = planta com $1 / 3$ das folhas murchas; 2 = planta $\operatorname{com} 2 / 3$ das folhas murchas; 3 = planta totalmente murcha; 4 = planta morta. 


\section{Resultados e discussão}

As médias de halo de inibição dos extratos de melão de são caetano $M$. charantia, catingueira $C$. pyramidalis e mussambê $C$. hassleriana, ajustaram-se ao modelo linear de regressão, enquanto que os extratos de pau-ferro $C$. leiostachya, erva de santa maria D. ambrosioides, juazeiro Z . joazeiro e quixabeira $S$. obtusifolium ajustaram-se ao modelo quadrático já as médias do extrato de ariú não ajustaram-se a nenhum modelo de regressão porém houve formação de halo nas concentrações testadas (Tabela 3).

Tabela 3. Regressão da análise de variância para formação de halo de inibição bacteriano em função dos diferentes extratos utilizados no antibiograma.

\begin{tabular}{|c|c|c|c|c|c|c|c|c|}
\hline Fonte de variação & AR & PF & ESM & JUA & QXB & MSC & CAT & MSB \\
\hline Regressão linear & $0.0251^{\mathrm{ns}}$ & $1.0771^{\mathrm{ns}}$ & $0.387 \mathrm{~ns}$ & $0.063^{\mathrm{ns}}$ & $3.54 \mathrm{~ns}$ & $21.49^{* *}$ & $20.35^{* *}$ & $13.36^{* *}$ \\
\hline Regressão quad. & $2.7848^{\mathrm{ns}}$ & $12.3308^{* *}$ & $9.105^{* *}$ & $23.39^{* *}$ & $7.013^{*}$ & $0.358^{\mathrm{ns}}$ & $2.114^{\mathrm{ns}}$ & $22.12^{* *}$ \\
\hline Regressão cúbica & $4.2394^{\mathrm{ns}}$ & $5.3602^{*}$ & $0.457 \mathrm{~ns}$ & $4.12^{\mathrm{ns}}$ & $10.48^{* *}$ & $1.114^{\mathrm{ns}}$ & $0.919 \mathrm{~ns}$ & $1.368^{* *}$ \\
\hline Regressão $4^{\circ}$ grau & $0.0134^{\mathrm{ns}}$ & $0.6094^{\mathrm{ns}}$ & $2.322^{\mathrm{ns}}$ & $1.53^{\mathrm{ns}}$ & $10.7^{\text {** }}$ & $0.237^{\mathrm{ns}}$ & $1.366^{\mathrm{ns}}$ & $20.19^{n s}$ \\
\hline $\mathrm{CV} \%$ & 122.74 & 63.05 & 83.24 & 56.60 & 49.75 & 54.88 & 52.71 & 40.06 \\
\hline
\end{tabular}

*Significativo ao nível de $5 \%$ de probabilidade $(01=<\mathrm{p}<0,05)$ pelo teste $\mathrm{F},{ }^{* *}$ significativo ao nível de $1 \%$ de probabilidade $(\mathrm{p}<0,01)$, ns = não significativo $(\mathrm{p}>0,05)$. Legenda: $\mathrm{AR}=$ Chrysobalanus icaco; $\mathrm{PF}=$ Caesalpinia leiostachya $; \mathrm{ESM}=$ Dysphania ambrosioides; $\mathrm{JUA}=$ Ziziphus joazeiro; $\mathrm{QXB}=$ Sideroxylon obtusifolium; $\mathrm{MSC}=$ Momordica charantia $;$ CAT = Caesalpinia pyramidalis; $\mathrm{MSB}=$ Cleome hassleriana.

Os extratos de M. charantia, C. pyramidalis e Cleome hassleriana proporcionaram uma maior inibição do crescimento da $R$. solanacearum, formando halos de inibição com médias de $1,47 \mathrm{~cm}, 1,52 \mathrm{~cm}$ e $1,68 \mathrm{~cm}$, respectivamente, na maior concentração $(80 \mathrm{mg} / \mathrm{mL})$ (Figuras $2 \mathrm{~A}, 2 \mathrm{~B}$ e $2 \mathrm{C}$ ).

Oliveira et al. (2020) em estudo com M. charantia destaca a presença de alcaloides, catequinas, esteroides, saponinas, flavonas, flavonóis, flavononóis e xantonas, tais compostos também são encontrados nas plantas das pesquisas. Compostos esses que conferem as plantas atividade antimicrobiana.

Em estudos conduzidos com o patógeno de solo Phytium sp., o extrato de mussambê demonstrou potencialidade, diminuindo a severidade da doença (Lazzeri e Manici, 2001), bem como o crescimento micelial de Alternaria alternata, quando utilizado o extrato etanólico (Pinto et al., 2018).

O extrato de ariú, não ajustou a nenhum modelo de regressão e apresentou média de halos de 0,118 cm, inferior inclusive as medidas verificadas nos demais extratos, mesmo nas concentrações mais baixas (Figura 2D).

Os extratos do juazeiro $Z$. joazeiro, erva de santa maria D. ambrosioide, quixabeira S. obtusifolium e pau ferro C. leiostachya, tiveram um comportamento semelhante e promoveram a formação de maiores halos de inibição de crescimento bacteriano nas concentrações intermediárias que variaram de $40 \mathrm{mg} / \mathrm{mL}$ (juazeiro) a $47,5 \mathrm{mg} / \mathrm{mL}$ (quixabeira), tendo sido, dentre estes, o extrato de pau-ferro o que proporcionou a formação de maiores halos, com média de 1,15 cm (Figura 2E, 2F, 2G e 2H).

Estudo farmacológico avaliando atividades antifúngicas dos extratos de C. pyramidalis, S. obtusifolium e Z. joazeiro na concentração de $4 \mathrm{mg} / \mathrm{mL}$ com metodologia de difusão em disco frente a isolados clínicos de Cryptococcus neoformans realizado por Barbosa Júnior et al. (2015), obteve resultados promissores havendo halo de inibição na concentração testada, os autores relatam a necessidade de mais estudos para corroborar com os resultados encontrados. 

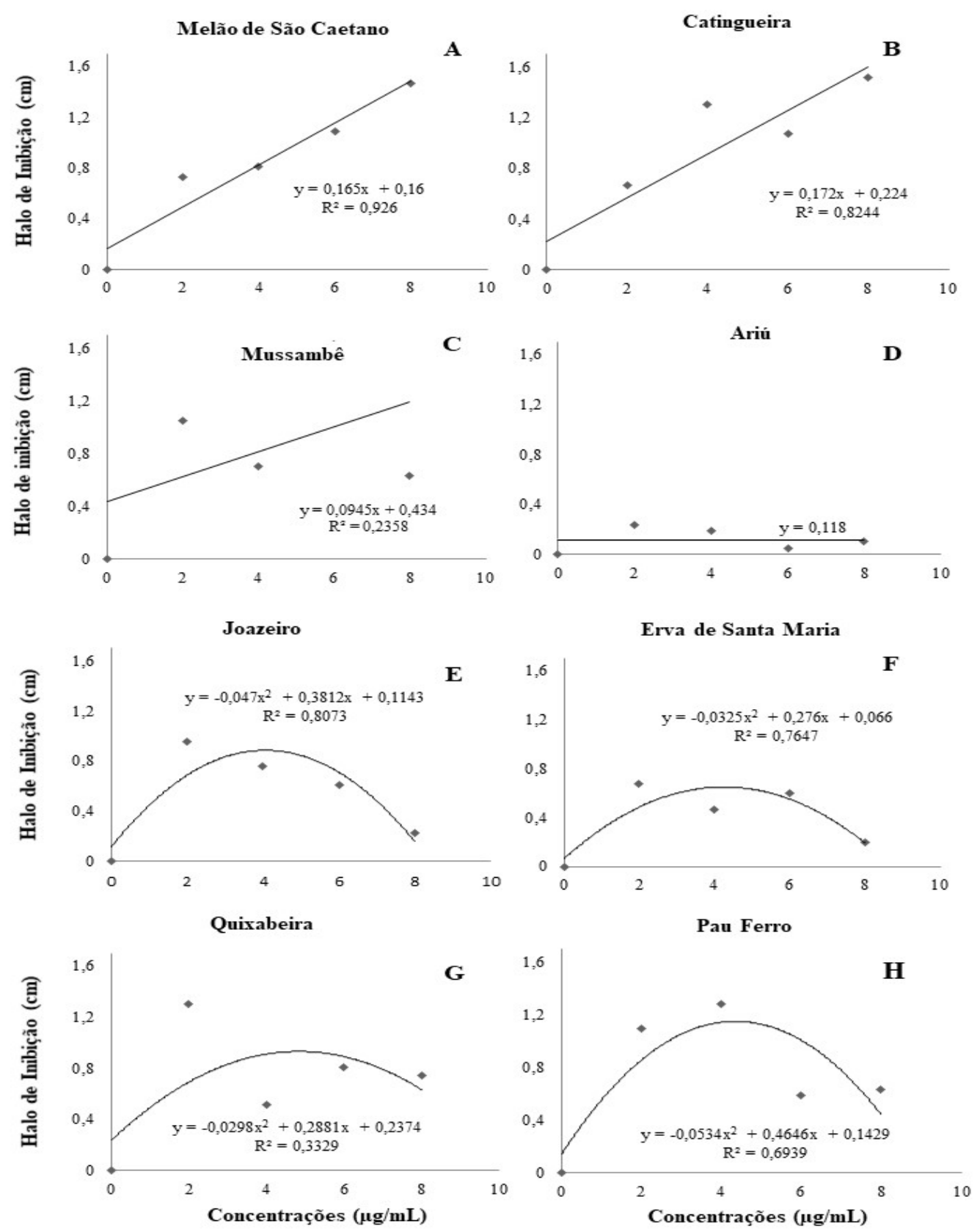

Figura 2. Extratos vegetais aquosos, com as diferentes doses sobre a formação de halo de inibição de crescimento de R. solanacearum.

O Z. joazeiro é explorado categoricamente em inúmeros estudos em patologias humanas, associados principalmente às doenças peridentais. Em virtudes de elevadas taxas de infecções causadas por bactérias resistentes a antibióticos já comercializados, inúmeras pesquisas têm sido desenvolvidas com objetivo de descobrir novos agentes antibacterianos. Foi descrito como resultado de caracterização fitoquímica do extrato o metabolitos saponinas, taninos, cumarinas e alcaloides (Sousa et al., 2018). Em estudo agronômico realizado in vitro avaliando atividade antifúngica do extrato etanólico de Z. joazeiro frente a Alternaria alternata não houve inibição do crescimento micelial nas doses avaliadas (Pinto et al., 2018). 
Sampaio et al. (2017) avaliando o potencial antimicrobiano in vitro de extrato de quixabeira $S$. obtusifolium contra bactérias patogênicas ao homem e sua composição química, verificaram que a presença de flavonoides, fenóis e taninos, compostos importantes para a defesa vegetal e que podem estar associados a atividade antimicrobiana contra uma série de patógenos.

Os testes de médias para as variáveis epidemiológicas: Período de incubação (PI); Severidade (S); Área Abaixo da Curva de Progresso da Doença (AACPD) e de percentagem de proteção da murcha bacteriana do tomateiro, em função dos diferentes extratos vegetais aquosos na concentração de $40 \mathrm{mg} / \mathrm{mL}$, aplicados via solo estão demonstrados na Tabela 4. 0 surgimento dos primeiros sintomas variou entre os tratamentos de sete (testemunha relativa) a 16 dias (quixabeira), no entanto, não foram observadas diferenças significativas entre os tratamentos para esta variável. A testemunha absoluta não evidenciou nenhum sintoma até o final do período de avaliações (Tabela 4).

Tabela 4. Análise de Variância para os componentes epidemiológicos da doença em função dos diferentes tratamentos (extratos vegetais e indutor de resistência).

\begin{tabular}{|l|c|c|c|c|}
\hline & PI (Dias) & SEV & AACPD & PROTEÇ̃̃O (\%) \\
\hline Tab $^{* * *}$ & -- & $0,0 \mathrm{~b}$ & $0,0 \mathrm{~d}$ & $100,0 \mathrm{a}$ \\
\hline Trel & $7,0 \mathrm{a}^{* *}$ & $4,0 \mathrm{a}$ & $35,0 \mathrm{a}$ & $0,0 \mathrm{e}$ \\
\hline PF & $11,0 \mathrm{a}$ & $3,3 \mathrm{a}$ & $27,3 \mathrm{ab}$ & $20,6 \mathrm{de}$ \\
\hline MSC & $9,0 \mathrm{a}$ & $2,3 \mathrm{ab}$ & $19,16 \mathrm{bc}$ & $43,6 \mathrm{~cd}$ \\
\hline CAT & $11,3 \mathrm{a}$ & $2,7 \mathrm{ab}$ & $23,37 \mathrm{abc}$ & $31,2 \mathrm{cde}$ \\
\hline QXB & $16,0 \mathrm{a}$ & $1,0 \mathrm{ab}$ & $4,5 \mathrm{~d}$ & $26,8 \mathrm{ab}$ \\
\hline AR & $12,3 \mathrm{a}$ & $3,3 \mathrm{a}$ & $24,7 \mathrm{abc}$ & $5,5 \mathrm{cde}$ \\
\hline ESM & $9,7 \mathrm{a}$ & $3,0 \mathrm{ab}$ & $34,3 \mathrm{a}$ & $10,3 \mathrm{de}$ \\
\hline JUA & $10,3 \mathrm{a}$ & $2,7 \mathrm{ab}$ & $32,2 \mathrm{ab}$ & $25,0 \mathrm{de}$ \\
\hline MSB & $11,7 \mathrm{a}$ & $4,0 \mathrm{a}$ & $25,5 \mathrm{abc}$ & $62,7 \mathrm{bc}$ \\
\hline BABA & $13,7 \mathrm{a}$ & $2,7 \mathrm{ab}$ & $12 \mathrm{~cd}$ & 33,02 \\
\hline \multicolumn{1}{|c|}{ CV $(\%)$} & 29,75 & 43.81 & 23.51 & \\
\hline
\end{tabular}

PI - Período de incubação; SEV - Severidade; AACPD - Área abaixo da curva de progresso da doença; ${ }^{* *}$ Dentro de cada coluna, valores seguidos de letras distintas são significativamente diferentes, de acordo com o teste de Tukey, ao nível de $5 \%$ de probabilidade.

${ }^{* * *} \mathrm{Tab}=$ Testemunha absoluta; Treal = Testemunha relativa; $\mathrm{PF}=$ Caesalpinia leiostachya; $\mathrm{MSC}=$ Momordica charantia; $\mathrm{CAT}=$ Caesalpinia pyramidalis; $\mathrm{QXB}=$ Sideroxylon obtusifolium; $\mathrm{AR}=$ Chrysobalanus icaco; $\mathrm{ESM}=$ Dysphania ambrosioides; JUA = Ziziphus joazeiro; $\mathrm{MSB}=$ Cleome hassleriana; $\mathrm{BABA}=$ Ácido D-L-aminobutírico.

A menor severidade final da doença ( 0 ) foi observada na testemunha absoluta, que não diferiu dos tratamentos Melão de São Caetano, Catingueira, Quixabeira, Erva de Santa Maria, Joazeiro e o indutor BABA, no entanto, a maior severidade foi verificada no tratamento relativo, com a nota máxima da escala diagramática (4) que indica a morte da planta, mas diferiu apenas da testemunha absoluta (Tabela 4).

A testemunha absoluta obteve a menor AACPD (0), uma vez que não foi inoculado com o patógeno e, portanto, não exibiu nenhum tipo de sintoma e este, não diferiu do tratamento quixabeira e também das plantas tratadas com o indutor BABA. As plantas tratadas com o extrato de quixabeira, proporcionaram uma proteção de $86,8 \%$ contra a doença, tendo sido o único tratamento a não diferir da testemunha relativa (100\%), não diferindo também do tratamento BABA $(62,7 \%)$. 
Aquino et al. (2016) traçando o perfil fitoquímico do extrato das folhas de S. obtusifolium, obteve como resultado uma elevada quantidade fenóis totais que se caracterizam por ser um grupo bastante heterogêneo, com atividade de proteger as plantas contra estresses bióticos. Triagem fitoquímica realizada por Barbosa et al. (2019), concluiu que, tanto extratos de folhas quanto de casca tem presença de metabólitos semelhantes corroborando com informações usadas nas comunidades populares no tratamento de inflamações.

A quixabeira é utilizada na medicina popular por seu efeito anti-inflamatório e sua atividade antioxidante (Odontuya et al., 2005). Leite et al. (2015) já relatou a presença de flavonoides e terpenóides neste vegetal, bem como alguns polifenóis (ácido gálico, quercetina, kaemferol, ácido ferúlico) (Pinto et al., 2018). Todos estes compostos desempenham importantes funções na defesa vegetal contra a fitopatógenos.

0 uso do ácido D-L-aminobutírico, é considerado um eliciador exógeno sendo estudado na proteção e na indução de resistência em plantas, desempenhando um papel importante para estimular ação oxidativa vegetal durante estágios iniciais de infecção (Chavan et al., 2013). Yan et al. (2010) relatam que o BABA contribui com estabelecimento de resistência sistêmica em tubérculos de batatas infectadas com Fusarium sulphureum durante o armazenamento sendo promissor para a utilização.

Gurgel et al. (2005) avaliando o indutor em plantas de tomate com 50 dias após semeadura, inoculadas com Fusarium oxysporum Schlecht f.sp. lycopersici verificou uma redução significativa no índice de doença. Martínez-Aguilar et al. (2016), em experimento realizado com Phaseolus vulgaris L. infectados artificialmente com Pseudomonas syringae pv. Phaseolicola obtiveram uma redução de $44,45 \%$ no tamanho da lesão nas plantas tratadas com o BABA. Já Medeiros (2017) analisando o indutor em plantas de mandioca infectadas com Scytaliduim lignicola agente causal da podridão radicular, não obteve resultados satisfatórios em condições de casa de vegetação e determinações enzimáticas vegetais.

\section{Conclusões}

Os extratos aquosos de M. charantia L., Caesalpinia pyramidalis Tul. e Cleome hassleriana possuem elevada atividade antimicrobiana in vitro de $R$. solanacearum na dose $80 \mathrm{mg} / \mathrm{mL}$ e Caesalpinia leiostachya na dose de $42,5 \mathrm{mg} / \mathrm{mL}$. Os extratos aquosos de Ziziphus joazeiro (40 mg/mL) Mart. Dysphania ambrosioides $(42,5 \mathrm{mg} / \mathrm{mL}$ ) e Sideroxylon obtusifolium $(50 \mathrm{mg} / \mathrm{mL})$ apresentam potencial antimicrobiano mediano no desenvolvimento in vitro de R. solanacearum.

O extrato de Chrysobalanus icaco L. não apresentou atividade antibacteriana in vitro contra $R$. solanacearum. 0 extrato aquoso de Sideroxylon obtusifolium $(40 \mathrm{mg} / \mathrm{mL}$ ) e o indutor de resistência BABA (DOSE) constituem-se em importantes ferramentas no manejo da murcha bacteriana do tomateiro em condições de casa de vegetação por reduzir de forma acentuada a AACDP e promover elevados índices de proteção da planta contra a doença.

\section{Conflito de interesses}

Os autores declaram não haver conflito de interesses. 


\section{Referências}

Agrios, G. N. Plant pathology. 5. ed. Amsterdam: Elsevier, 2005.

Aquino, P.; Figueredo, F. G.; Pereira, N.; Nascimento, E.; Martin, A.; Veras, H.; Oliveira, C.; Ferreira, S.; Leandro, L.; Silva, M.; Menezes, I. Evaluation of the topical anti-inflammatory activity and antibacterial activity of methanol extract in the Sideroxylon obtusifolium leaves. Acta Biológica Colombiana, v. 21, p. 131-140, 2016. https://doi.org/10.15446/ abc.v21n1.48170

Barbosa Junior, A. M.; Melo, D. L. F. M.; Almeida, F. T. C.; Trindade, R. C. Comparative study of the susceptibility of clinical isolates of Cryptococcus neoformans (Sanfelice) against some antifungal agents of hospital use and plant extracts obtained from medicinal plants of the semiarid Sergipe region, Brazil. Revista Brasileira de Plantas Medicianais, v. 17, p. 120-132, 2015. https://doi.org/10.1590/1983-084X/11_177

Barbosa, D. A.; Lucena, R. F. P.; Cruz, D. D. Traditional knowledge as basis for phytochemical prospecting of Sideroxylon obtusifolium (Roem. \& Schult.) T. D. Penn. aiming at conservation in the Brazilian semi-arid zone. Ethnobotany Research and Applications, v. 18, p. 1-10, 2019.

Bettiol, W.; Silva, J. C.; Castro, M. L. P. Uso atual e perspectivas do Trichoderma no Brasil. In: Meyer, M. C. Trichoderma: uso na agricultura. Brasília: EMBRAPA, 2019.

Camargo Filho, W. P.; Camargo, F. P. Evolução das cadeias produtivas de tomate industrial e para mesa no Brasil. Informações Econômicas, v. 47, p. 50-59, 2017. Disponível em: <http://www.iea.sp.gov.br/ftpiea/ie/2017/tec4-0117.pdf>. Acesso em: 23 jan. 2020.

Canuto, C.; Andrade, D. S.; Lima, E. M.; Goes, M. C. C.; Almeida, M. M. V.; Lima, J. R. S. Biochar e esterco bovino aumentam a eficiência no uso de água da alface. Diversitas Journal, v. 4, p. 1082-1091, 2019. https://doi.org/10.17648/diversitas-journal-v4i3.822

Chavan, V.; Bhargava, S.; Kamble, A. C. Temporal modulation of oxidant and antioxidative responses in Brassica carinata during $\beta$-aminobutyric acid-induced resistance against Alternaria brassicae. Patologia Fisiológica e Molecular das Plantas, v. 83, p. 35-39, 2016. https://doi.org/10.1016/j.pmpp.2013.03.002

Costa, K. D. S. Controle genético da resistência do tomateiro 'Yoshimatsu' a Ralstonia pseudosolanacearum e a Ralstonia solanacearum. Recife: Universidade Federal Rural de Pernambuco, 2017. (Tese de doutorado).

Costa, R. C.; Ishida, A. K. N.; Miranda, V. S.; Filho, A. S. D.; Silva, C. T. B.; Resende, M. L. V.; Oliveira, L. V. Extratos vegetais, formulações à base de extrato vegetal e produtos químicos no controle da mancha bacteriana do maracujazeiro. Revista Brasileira de Agropecuária Sustentável, v. 7, p. 26-33, 2017. https://doi.org/10.21206/rbas.v7i1.375

Gurgel, L. M. S.; Oliveira, S. M. A.; Coelho, R. S. B.; Silva, L. X. Proteção à murcha de fusário do tomateiro com acibenzolar-S-metil e ácido $\beta$-aminobutírico. Fitopatologia Brasileira, v. 30, p. 655-657, 2005. https://doi.org/10.1590/S0100-41582005000600015

IBGE - Instituto Brasileiro de Geografia e Estatística. Levantamento sistemático da produção agrícola-LSPA. Rio de Janeiro: IBGE, 2019. Disponível: <https://www.ibge.gov.br/estatisticas/economicas/agriculturaepecuaria/9201levantame ntosistematico-da-producao-agricola.html>. Acesso em: 23 jan. 2020.

Lazzeri, L.; Minici, L. M. Allelopathic effect of glucosinolate-containing plant green manure on Pythium sp. and total fungal population in soil. Horticulture Science, v. 36, p. 1283-1289, 2001. https://doi.org/10.21273/HORTSCI.36.7.1283 
Leite, N. S.; Lima, A. P.; Araújo-Neto, V.; Estevam, C. S.; Pantaleão, S. M.; Camargo, E. A.; Fernandes, R. P. M.; Costa, S. K. P.; Muscará, M. N.; Thomazzi, S. M. Avaliação das atividades cicatrizante, anti-inflamatória tópica e antioxidante do extrato etanólico de Sideroxylon obstusifolium (quixabeira). Revista Brasileira de Plantas Medicinais, v. 17, n. 1, p. 164-170, 2015. https://doi.org/10.1590/1983-084X/09_189

Lopes, C. A.; Boiteux, L. S.; Eschemback, V. Eficácia relativa de porta-enxertos comerciais de tomateiro no controle da murcha-bacteriana. Horticultura Brasileira, v. 33, p. 125-130, 2015. https://doi.org/10.1590/S0102-053620150000100020

Martínez-Aguilar, K.; Ramírez-Carrasco, G.; Hernández-Cháves, J. L.; Barraza, A.; AlvarezVenega, R. Use of BABA and INA as activators of a primed state in the common bean (Phaseolus vulgaris L.). Frontiers in Plant Science, v. 7, 2016. https://doi.org/10.3389/ fpls.2016.00653

Medeiros, M. B. C. L. Mecanismos bioquímicos e fisiológicos na cultura da mandioca (Manihot esculenta Crantz) submetidas a diferentes indutores de resistência. Garanhuns: Universidade Federal Rural de Pernambuco, 2017. (Dissertação de mestrado).

Mello, A. P. O. A.; Zacharias, M. B. Efeito de extrato vegetal de Schinus terebinthifolius no crescimento micelial de Colletotrichum acutatum do morangueiro. Ciência, Tecnologia \& Ambiente, v. 9, 09151, 2019. https://doi.org/10.4322/2359-6643.09151

Mendes, A. Q. Resistência à murcha bacteriana em linhagens e híbridos de tomateiro. Recife: Universidade Federal Rural do Pernambuco, 2017. (Tese de doutorado).

Odontuya, G.; Hould, J. R. S.; Houghton, P. J. Structutr-acivity relationshio for antiinflammatory effect of luteolin and its derived glycosides. Phytotherapy Research, v. 19, p. 782-786, 2005. https://doi.org/10.1002/ptr.1723

Oliveira, S. C.; Andrade Filha, G. K. S.; Lopes, J. M. S. Uso da planta "melão de são caetano" (Momordica charantia L.) no combate ao carrapato (Rhipicephalus sanguineus) de cães: revisão de literatura. Brazilian Journal of Development, v. 6, n. 4, p. 22688-22713, 2020. https://doi.org/10.34117/bjdv6n4-436

Pinto, K. M. S.; Melo, P. A. F. R.; Nascimento, L. C.; Cortez, M. I. G. M.; Aires, A. A. C.; Mondego, J. M.; Lima, R. P.; Silva, E. C.; Mesquita, M. L. R.; Lemos, R. N. S. Biological potential of extracts of Caatinga plants in the control of Alternaria alternata f. sp. citri in Citrus. Journal of Agricultural Science, v. 10, p.650-656, 2018. https://doi.org/10.5539/ jas.v10n12p116

Sampaio, T. P. D.; Cartaxo-Furtado, N. A. O.; Medeiros, A. C. D.; Alves, H. S. Antimicrobial potential of plant extracts and chemical fractions of Sideroxylon obtusifolium (Roem. \& Schult.) T.D. Penn on oral microorganisms. The Jornal of Contemporary Dental Practice, v. 18, p. 392-398, 2017. https://doi.org/10.5005/jp-journals-10024-2053

Silva, F. J. A.; Michereff, S. J. Quantificação de fitobacterioses. In: Gama, M. A. S.; Nicoli, A.; Guimarães, L. M. P.; Lopes, U. P.; Michereff, S. J. Estado da arte em fitobacterioses tropicais. Recife: UDUFRPE, 2016.

Sousa, I. J. O.; Silva, M. C. P.; Leopoldino, G. L.; Agostinho, L. S. Estudo fitoquímico, avaliação da capacidade hemolítica e antimicrobiana de um extrato bruto da casca do caule de Ziziphus joazeiro Mart. (Rhamnaceae). Journal of Biology \& Pharmacy and Agricultural Management, v. 14, p. 208-225, 2018. Disponível em: <http://revista.uepb.edu.br/ index.php/biofarm/article/view/3496>. Acesso em: 23 jan. 2020. 
Yan, Y.; Yong-Cai, L.; Yang, B.; Song-jiang, C.; Ying-chao, L.; Li, Y.; Yi, W.; Di, W. Postharvest treatment with $\beta$-aminobutyric acid induces resistance against dry rot caused by Fusarium sulphureum in potato tuber. Agricultural Sciences in China, v. 9, p. 1372-1380, 2010. https://doi.org/10.1016/S1671-2927(09)60228-5

(CC) Attribution, que permite uso irrestrito, distribuição e reprodução em qualquer meio, desde que a obra original seja devidamente citada. 